\title{
Increasing presence of xylazine in heroin and/or fentanyl deaths, Philadelphia, Pennsylvania, 2010- 2019
}

\author{
Jewell Johnson 지 , Lia Pizzicato, Caroline Johnson, Kendra Viner
}

Philadelphia Department of Public Health, Philadelphia, Pennsylvania, USA

\section{Correspondence to}

Jewell Johnson, Philadelphia Department of Public Health, Philadelphia, PA 19107, USA; jewell.johnson@phila.gov

Received 18 August 2020 Revised 2 November 2020 Accepted 13 November 2020 Published Online First 3 February 2021

\section{Check for updates}

(c) Author(s) (or their employer(s)) 2021. No commercial re-use. See rights and permissions. Published by BMJ.

To cite: Johnson J, Pizzicato L, Johnson C, et al. Inj Prev 2021;27:395-398.

\section{ABSTRACT}

Reports from active drug users state that xylazine, the veterinary tranquilliser, has been increasing in the illicit drug supply in Philadelphia. To describe trends and characteristics of unintentional deaths from heroin and/or fentanyl overdose with xylazine detections occurring in Philadelphia, Pennsylvania, the Philadelphia Department of Public Health analysed data on deaths from unintentional heroin and/or fentanyl overdose from the Philadelphia Medical Examiner's Office over a 10-year period (2010-2019). Xylazine went from being detected in less than $2 \%$ cases of fatal heroin and/ or fentanyl overdose between 2010 and 2015 to 262 (31\%) of the 858 fatal heroin and/or fentanyl overdose cases in 2019. Currently, information is limited on the presence of xylazine in continental United States. Xylazine's association with adverse outcomes in other locations indicates that potential health consequences should also be monitored in the USA. Whenever possible, jurisdictions should consistently test for xylazine.

\section{INTRODUCTION}

Xylazine is a non-opioid sedative, analgesic, and muscle relaxant used in veterinary medicine. ${ }^{1}$ Human use of xylazine among people who take drugs has been well documented in Puerto Rico since the early 2000s, where it is known as 'anestesia de caballo' (horse anaesthetic). ${ }^{2-4}$ Increasingly, there have been reports of xylazine in the illicit drug supply in continental United States although motivations for its addition to the drug supply are unclear. ${ }^{56}$ In the USA, xylazine is not a scheduled medication, and although it is approved for use in veterinary medicine, the Food and Drug Administration has not approved it for human use. In humans, xylazine may cause hypotension, central nervous system depression, respiratory depression and bradycardia. ${ }^{1}$ In addition, associations have been made between the use of xylazine and open skin ulcers among individuals who inject it. ${ }^{2} 4$ Research is limited on the effects of xylazine when used in combination with opioids and information on its presence in continental USA, especially in fentanyl dominated markets. In Philadelphia, the street name for xylazine is 'tranq', and heroin and fentanyl cut with xylazine is referred to as 'tranq dope'. This study examines trends in xylazine detections in postmortem toxicology tests among overdose decedents in Philadelphia, Pennsylvania, a city where fentanyl has largely replaced heroin in the illicit drug market since 2015 .

\section{METHODS}

Using data from the Philadelphia Medical Examiner's Office (MEO), the Philadelphia Department of Public Health analysed unintentional overdose deaths with heroin and/or fentanyl detections that occurred between 2010 and 2019 in Philadelphia. Records were limited to deaths where drug intoxication was certified as the underlying or contributory cause of death, and full forensic toxicology testing was performed by the MEO. Full toxicology data of all drug detections at death were provided by the MEO for this analysis. For the duration of the study period, the Philadelphia MEO consistently tested for xylazine, fentanyl and heroin when conducting post mortem toxicology tests among overdose decedents. Overdose deaths among Philadelphia residents occurring outside of the city were excluded as full forensic toxicology was not available for these decedents. Non-residents who died in the city and were investigated by the Philadelphia MEO were included in the study sample. Given the increase in xylazine detections in 2019, we examined age, sex, race/ethnicity and additional toxicology detections among 2019 overdose decedents positive for heroin and/or fentanyl and stratified by the presence of xylazine. Chi-square tests were used to examine differences in categorical variables, and an alpha level of 0.05 was considered significant. We also analysed data on polydrug samples seized in Pennsylvania and tested by a Drug Enforcement Administration laboratory. Samples in which the primary drug (ie, the drug detected in the highest quantity) was heroin or fentanyl were examined for the presence of xylazine. Analyses were conducted using SAS (Studio; SAS Institute).

\section{RESULTS}

Between 2010 and 2015, xylazine was detected in $40(2 \%)$ of the 1854 unintentional overdose deaths with heroin and/or fentanyl detections. This increased to $67(11 \%)$ in 2016, 90 (10\%) in 2017, $152(18 \%)$ in 2018, and 262 (31\%) in 2019 (figure 1).

In 2019, decedents with positive xylazine detections were predominately male $(76 \%)$, between the ages of 35 and 54 years old (47\%) and nonHispanic, white (65\%). Age, race/ethnicity and opioid detections were statistically different from those of heroin and/or fentanyl decedents without xylazine detected (table 1). Among 2019 decedents with positive detections for xylazine, $100 \%$ were positive for fentanyl, 10\% were positive for heroin, 


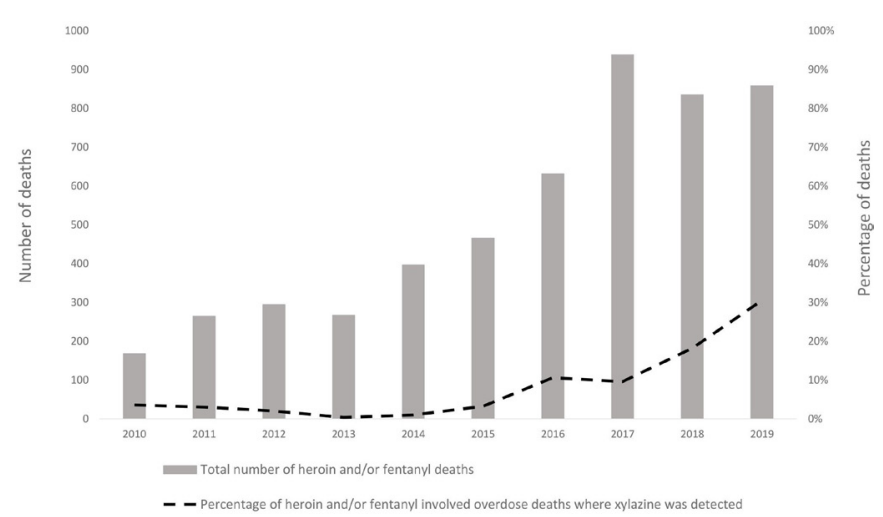

Figure 1 Number and percentage of heroin and/or fentanyl unintentional overdose deaths involving xylazine, Philadelphia, Pennsylvania, 2010-2019.

$7 \%$ were positive for pharmaceutical opioids such as oxycodone, $6 \%$ were positive for methadone, $12 \%$ were positive for methamphetamine, $28 \%$ were positive for benzodiazepines and $53 \%$ were positive for cocaine (table 1). Evidence of injection was more prevalent among heroin and/or fentanyl decedents who were positive for xylazine than for those who were not $(\mathrm{p}<0.0001)$ (table 1).

Drug seizure data tested in Drug Enforcement Administration laboratories indicates that xylazine is increasing in polydrug samples in which the primary drug detected is heroin or fentanyl.

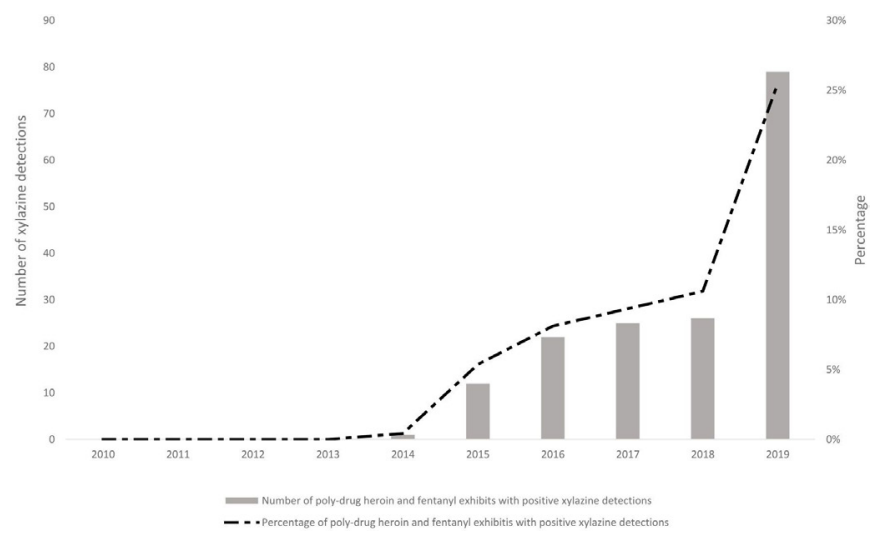

Figure 2 Number and percentage of xylazine detections in polydrug exhibits seized where the primary drug detected was fentanyl or heroin, Pennsylvania, 2010-2019.

While no polydrug seizures contained xylazine between 2010 and 2013, 5\% contained xylazine in 2015, 9\% in 2017 and $25 \%$ in 2019 (figure 2).

\section{DISCUSSION}

Harms of xylazine use in humans are not well documented, but evidence suggests that combined use of xylazine and an opioid such as fentanyl may increase the risk of overdose fatality. ${ }^{1}$ Although naloxone, the opioid overdose reversal drug, is

Table 1 Demographic characteristics and toxicology detections of heroin and/ or fentanyl overdose decedents ( $\mathrm{n}=858$ ), Philadelphia, Pennsylvania, 2019

\begin{tabular}{|c|c|c|c|c|c|}
\hline & \multicolumn{2}{|c|}{$\begin{array}{l}\text { Heroin and/or fentanyl without xylazine } \\
(n=596)\end{array}$} & \multicolumn{2}{|c|}{$\begin{array}{l}\text { Heroin and/or } \\
\text { fentanyl with } \\
\text { xylazine } \\
(n=262)\end{array}$} & \multirow{2}{*}{$\begin{array}{l}\text { Chi Square } \\
\text { P value }\end{array}$} \\
\hline & $\mathrm{N}$ & $\%$ & $\mathrm{~N}$ & $\%$ & \\
\hline \multicolumn{6}{|c|}{ Demographic characteristics } \\
\hline Age (years) & & & & & 0.0381 \\
\hline $15-34$ & 172 & 28.9 & 94 & 35.9 & \\
\hline $35-54$ & 285 & 47.8 & 124 & 47.3 & \\
\hline$\geq 55$ & 139 & 23.3 & 44 & 16.8 & \\
\hline Sex & & & & & 0.9710 \\
\hline Male & 452 & 75.8 & 199 & 76.0 & \\
\hline Female & 144 & 24.2 & 63 & 24.0 & \\
\hline Race/ethnicity & & & & & $<0.0001$ \\
\hline Non-Hispanic, white & 293 & 49.2 & 169 & 64.5 & \\
\hline Non-Hispanic, black & 185 & 31.0 & 46 & 17.6 & \\
\hline Hispanic & 111 & 18.6 & 42 & 16.0 & \\
\hline Other & 7 & 1.2 & 5 & 1.9 & \\
\hline \multicolumn{6}{|l|}{ Toxicology } \\
\hline \multicolumn{6}{|c|}{ Additional substance detected at death* } \\
\hline Fentanyl & 576 & 96.6 & 262 & 100.0 & 0.0027 \\
\hline Heroint & 172 & 28.9 & 27 & 10.3 & $<0.0001$ \\
\hline Pharmaceutical opioids $\ddagger$ & 73 & 12.2 & 18 & 6.9 & 0.0185 \\
\hline Methadone & 21 & 3.5 & 15 & 5.7 & 0.1385 \\
\hline Methamphetamine & 50 & 8.4 & 31 & 11.8 & 0.1122 \\
\hline Benzodiazepines & 158 & 26.5 & 74 & 28.2 & 0.5984 \\
\hline Cocaine & 313 & 52.5 & 140 & 53.4 & 0.8040 \\
\hline Evidence of injection & & & & & $<0.0001$ \\
\hline No & 458 & 76.8 & 159 & 60.7 & \\
\hline Yes & 138 & 23.2 & 103 & 39.3 & \\
\hline
\end{tabular}

*Substances are not mutually exclusive as more than one additional substance may be detected at death.

theroin may include detections for morphine only.

†Excludes detections for methadone and fentanyl. 
not effective against xylazine alone, unintentional fatal overdoses with xylazine detections also had heroin and/or fentanyl detections in Philadelphia, indicating timely administration of naloxone is critical for preventing deaths. Additional treatment for xylazine poisoning may involve supportive care using intubation, ventilation and administration of intravenous fluid. ${ }^{1}$

Of note, as fentanyl has largely replaced the heroin supply in Philadelphia, xylazine has been increasingly found in combination with fentanyl. Some evidence suggests that the combination of xylazine and fentanyl in humans may potentiate the desired effect of sedation and the adverse effects of respiratory depression, bradycardia and hypotension caused by fentanyl alone, ${ }^{1}$ comparable to the synergistic effects of combining benzodiazepines with heroin and/or fentanyl. ${ }^{7}$ While benzodiazepines were detected in $97(58 \%)$ of the 168 unintentional overdose deaths with heroin and/or fentanyl detections in Philadelphia in 2010, this decreased to $232(28 \%)$ of the 858 unintentional overdose deaths with heroin and/or fentanyl detections in 2019. This decline may be the result of increasing demand for xylazine among people who use drugs in Philadelphia and/or changes in the illicit drug market as drug seizure data indicate that xylazine is increasing in polydrug samples. Indeed, focus groups with people who use drugs in Philadelphia have suggested that the addition of xylazine to fentanyl "makes you feel like you're doing dope (heroin) in the old days (before it was replaced by fentanyl)" when the euphoric effects lasted longer. Users have suggested that xylazine gives them 'the nod' that heroin provided prior to the replacement of fentanyl in the drug supply. In Puerto Rico, xylazine use has been associated with use of 'speedballs', the combined use of heroin and cocaine. ${ }^{23}$ In semistructured interviews, Puerto Rican drug users indicated that the addition of cocaine to heroin and xylazine combinations was used to balance the 'down' of heroin and xylazine. ${ }^{4}$ Among 2019 decedents with positive detections for xylazine and an opioid in Philadelphia, 53\% also had positive detections for cocaine, which may indicate speedball use locally (table 1 ).

Importantly, our results show that evidence of injection was more prevalent among decedents with xylazine and heroin and/ or fentanyl detections. Despite limited literature on the health effects of chronic xylazine use, regular injection of xylazine has been associated with skin ulcers, abscesses and lesions in Puerto Rico. ${ }^{23}$ Semistructured interviews with people who use xylazine in Puerto Rico revealed that regular use of xylazine leads to skin ulcers. ${ }^{4}$ As skin ulcers are painful, people may continually inject at the site of the ulcer to alleviate the pain as xylazine is a potent $\alpha_{2}$-adrenergic agonist that mediates via central $\alpha_{2}$-receptors, which decreases perception of painful stimuli. ${ }^{1}$ People may selftreat the wound by draining or lancing it, which can exacerbate negative outcomes. ${ }^{8}$ While Philadelphia has seen a rise in skin and soft tissue infections relating to injection drug use, it is not yet clear whether or not this is due to increased presence of xylazine in the drug supply. ${ }^{9}$

The results from this study have some limitations. This study examined the presence of particular substances detected in post mortem toxicology among overdose decedents, but we were unable to determine which drug, or particular combination of drugs, caused the overdose death. Furthermore, we were unable to determine why xylazine is increasing in the drug supply (eg, increased street value, enhanced effects) or whether the decedent intended to use xylazine either alone or in combination with other drugs. While focus groups conducted in Philadelphia indicate that some people who use drugs have developed a preference for opioids combined with xylazine, we were unable to determine intent using toxicology data alone. Polydrug samples seized in Pennsylvania are enforcement driven and testing is done as required by courts. Thus, seizure data may not reflect the true prevalence of drugs at the street level. Findings from this study may not be generalisable outside of Philadelphia, and jurisdictions should independently assess whether xylazine is present in their illicit drug supply.

Results from this study suggests that the opioid epidemic throughout the USA continues to evolve. Although xylazine has been a drug of abuse in Puerto Rico since the early 2000s, fatal overdose toxicology data from Philadelphia and other jurisdictions suggest that its prevalence may be increasing in continental USA. ${ }^{5}$ Jurisdictions that do not currently test for xylazine should consider adding it to their routine toxicology testing. Further study is needed to understand the synergistic effects of fentanyl and xylazine use by humans and to better contextualise the reasons for its use in the USA.

\section{What is already known on the subject}

- Xylazine has been documented in Puerto Rico's illicit opioid supply since the early 2000 s.

- Xylazine has been associated with increased risk of skin ulceration and fatal overdose.

\section{What this study adds}

- Continental xylazine detections are evident in Philadelphia, Pennsylvania.

- While xylazine was detected in $2 \%$ of unintentional overdose deaths with heroin and/or fentanyl detections in Philadelphia during 2010-2015, detection increased to $31 \%$ by 2019.

- Prevalence of xylazine in overdose deaths may be underreported in the rest of continental USA as xylazine may not be consistently reported if forensic toxicology was not completed at death.

Acknowledgements We thank the Drug Enforcement Administration Philadelphia Division for providing data on xylazine seizures in Pennsylvania as well as the Philadelphia Medical Examiner's Office for providing data on unintentional overdose decedents.

Contributors JJ, LP, CJ and KV developed the study protocol. JJ and LP were responsible for the literature review. JJ performed the statistical analyses on data from the Philadelphia Medical Examiner's Office and LP performed the statistical analyses on the data from the Drug Enforcement Administration Philadelphia Division. JJ drafted the first version of the manuscript. LP, CJ and KV contributed to the interpretation of the results and assisted with manuscript revisions. All authors approved the submission of this version of the manuscript.

Funding This study was supported by the Centers for Disease Control and Prevention CDC-RFA-CE19-1904 awarded to the Philadelphia Department of Public Health.

Disclaimer The funders had no role in the study design, analysis and interpretation of data, and preparation and review of the manuscript.

Competing interests None declared.

Patient and public involvement Patients and/or the public were not involved in the design, or conduct, or reporting, or dissemination plans of this research.

Patient consent for publication Not required.

Ethics approval This study was determined to be exempt by the institutional review board at the City of Philadelphia Department of Public Health.

Provenance and peer review Not commissioned; externally peer reviewed.

ORCID iD

Jewell Johnson http://orcid.org/0000-0002-0478-1145 


\section{REFERENCES}

1 Ruiz-Colón K, Chavez-Arias C, Díaz-Alcalá JE, et al. Xylazine intoxication in humans and its importance as an emerging adulterant in abused drugs: a comprehensive review of the literature. Forensic Sci Int 2014;240:1-8.

2 Rodríguez N, Vargas Vidot J, Panelli J, et al. GC-MS confirmation of xylazine (Rompun), a veterinary sedative, in exchanged needles. Drug Alcohol Depend 2008;96:290-3.

3 Reyes JC, Negrón JL, Colón HM, et al. The emerging of xylazine as a new drug of abuse and its health consequences among drug users in Puerto Rico. J Urban Health 2012;89:519-26.

4 Torruella RA. Xylazine (veterinary sedative) use in Puerto Rico. Subst Abuse Treat Prev Policy 2011;6:7.

5 Maryland Poison Control Center. ToxTidbits: Xylazine [Internet]. Baltimore, MD. University of Maryland School of Pharmacy, 2019. Available: https://www.mdpoison.
com/media/SOP/mdpoisoncom/ToxTidbits/2019/Jan\%202019\%20ToxTidbits.pdf [Accessed 10 Jun 2020].

6 Ohio Department of Health. Health advisory: xylazine, an adulterant for illicit opioids, has been detected in three decedents who died from a drug overdose [Internet]. Columbus, OH. Ohio State Government, 2019. Available: http://rosscountyema.com/ wp-content/uploads/2019/05/Health-Advisory-Xylazine.pdf [Accessed 15 Jun 2020].

7 McClure FL, Niles JK, Kaufman HW, et al. Concurrent use of opioids and benzodiazepines: evaluation of prescription drug monitoring by a United States laboratory. J Addict Med 2017;11:420-6.

8 Harris RE, Richardson J, Frasso R, et al. Experiences with skin and soft tissue infections among people who inject drugs in Philadelphia: a qualitative study. Drug Alcohol Depend 2018;187:8-12.

9 Philadelphia Department of Public Health. Hospitalizations for infections related to injection drug use, 2013- 2018 [Internet], 2020. Available: https://www.phila.gov/ media/20200206154343/CHART-v5e1.pdf [Accessed 16 Jun 2020]. 